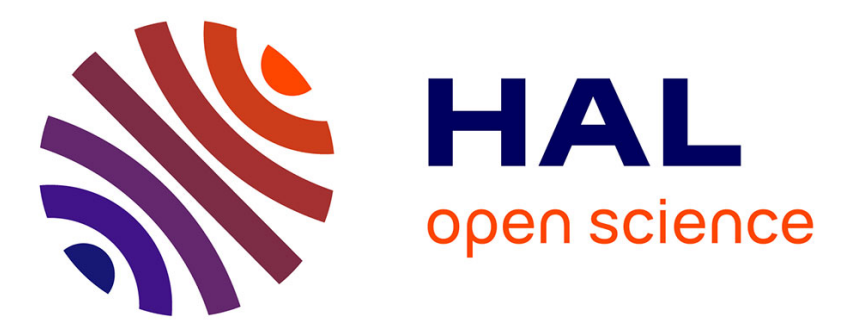

\title{
Influence of the initial supersaturation of solute atoms on the size of nanoparticles grown by an Ostwald ripening mechanism
}

Nikolay Cherkashin, Alain Claverie, Caroline Bonafos, V.V. Chaldyshev, N.A. Bert, V.V. Preobrazhenskii, M.A. Putyato, B.R. Semyagin, P. Werner

\section{To cite this version:}

Nikolay Cherkashin, Alain Claverie, Caroline Bonafos, V.V. Chaldyshev, N.A. Bert, et al.. Influence of the initial supersaturation of solute atoms on the size of nanoparticles grown by an Ostwald ripening mechanism. Journal of Applied Physics, 2007, 102 (2), pp.023520. 10.1063/1.2749303 . hal-01736067

\section{HAL Id: hal-01736067 https://hal.science/hal-01736067}

Submitted on 23 Mar 2018

HAL is a multi-disciplinary open access archive for the deposit and dissemination of scientific research documents, whether they are published or not. The documents may come from teaching and research institutions in France or abroad, or from public or private research centers.
L'archive ouverte pluridisciplinaire HAL, est destinée au dépôt et à la diffusion de documents scientifiques de niveau recherche, publiés ou non, émanant des établissements d'enseignement et de recherche français ou étrangers, des laboratoires publics ou privés. 
Influence of the initial supersaturation of solute atoms on the size of nanoparticles grown by an Ostwald ripening mechanism

N. A. Cherkashin, A. Claverie, C. Bonafos, V. V. Chaldyshev, N. A. Bert, V. V. Preobrazhenskii, M. A. Putyato, B. R. Semyagin, and P. Werner

Citation: Journal of Applied Physics 102, 023520 (2007); doi: 10.1063/1.2749303

View online: https://doi.org/10.1063/1.2749303

View Table of Contents: http://aip.scitation.org/toc/jap/102/2

Published by the American Institute of Physics

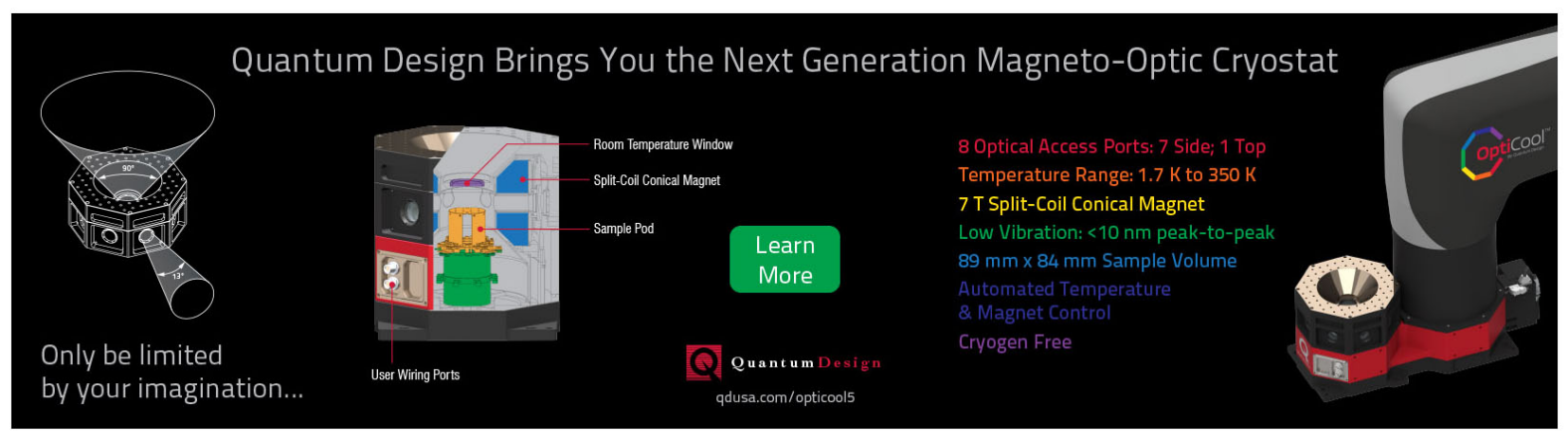




\title{
Influence of the initial supersaturation of solute atoms on the size of nanoparticles grown by an Ostwald ripening mechanism
}

\author{
N. A. Cherkashin ${ }^{\text {a) }}$ \\ CEMES-CNRS, nMat Group, 29 rue J. Marvig, 31055 Toulouse, France and Ioffe Physico-Technical \\ Institute, 26 Polytekhnicheskaya, St. Petersburg 194021, Russia
}

A. Claverie and C. Bonafos
CEMES-CNRS, nMat Group, 29 rue J. Marvig, 31055 Toulouse, France

V. V. Chaldyshev and N. A. Bert

Ioffe Physico-Technical Institute, 26 Polytekhnicheskaya, St. Petersburg 194021, Russia

V. V. Preobrazhenskii, M. A. Putyato, and B. R. Semyagin

Institute of Semiconductor Physics, Novosibirsk 630090, Russia

P. Werner

Max-Plank Institut fur Mikrostrukturphysik, Halle/Saale D-05120, Germany

(Received 6 December 2007; accepted 11 May 2007; published online 26 July 2007)

\begin{abstract}
We have designed a GaAs based structure in which the influence of the initial supersaturation of solute atoms, here As, on the nucleation and conservative growth of a precipitate phase during annealing can be studied. Size distributions and densities were extracted from transmission electron microscopy images under well defined and appropriate conditions, and the volume fraction that the precipitate phase occupies was deduced from these measurements for a variety of experimental conditions. We show that in the $0.06 \%-0.5 \%$ supersaturation range, the mean size of the precipitates obtained after annealing does not depend on the initial supersaturation of As atoms. On the other hand, the density of precipitates is proportional to this supersaturation. However, we observe that the increase of the precipitate volume fraction leads to a considerable broadening of the precipitate size distributions. The size invariance revealed here suggests that, for a volume fraction of less than $1 \%$, the populations are in quasiequilibrium with the supersaturated matrix and that the growth is driven by the interchange of As atoms (and vacancies) between the precipitates and the matrix and not directly from one precipitate to the next. It can be inferred that the diffusion fields surrounding the precipitates do not overlap much during the growth although some deviation from the expected shape of the size distribution may reveal the limitations of the nonlocal mean-field approximation suggested here. (C) 2007 American Institute of Physics. [DOI: 10.1063/1.2749303]
\end{abstract}

\section{INTRODUCTION}

Ostwald ripening is a thermal phenomenon during which particles interchange the atoms they are constituted of, in such a way that the largest particles grow at the expense of the smallest, making the whole population evolve. This phenomenon has received much attention recently as the thermal growth of many nanoparticles buried in different solid matrices, from nanocrystals, ${ }^{1-4}$ to extended defects, ${ }^{5-8}$ gas-filled cavities, and even voids, ${ }^{9,10}$ is apparently driven by this phenomenon. Nanoparticles, for example, i.e., particles with diameters in the range of a few nanometers, exhibit, often different, sometimes unique, properties compared to those found in the corresponding bulk materials. These properties can be directly due to the small sizes of the crystals, an example being the ability of semiconducting nanoparticles to confine carriers, or to the large surface-to-volume ratios they offer, which can lead to enhanced magnetic characteristics. However, the fine tuning of all these physical properties requires a perfect control over the characteristics of the popu-

\footnotetext{
${ }^{a)}$ Author to whom correspondence should be addressed; electronic mail: nikolay@cemes.fr
}

lations of nanoparticles. These characteristics include their size distribution and their density both defining the volume fraction that the precipitate phase occupies.

In most practical cases, these populations are obtained through the thermal precipitation of a second phase from a highly supersaturated solution containing the "impurity" atoms. This supersaturated solution can be obtained by growing the matrix material far from equilibrium conditions and in the preserve of a gas containing the impurity atoms or by directly injecting them into the matrix by using ion implantation. ${ }^{3,4}$ During annealing, small precipitates nucleate and grow following an Ostwald ripening mechanism during which they interchange their constituent atoms. There are a few fabrication parameters which can be tuned to manipulate the nanoparticle characteristics. The four most important are the annealing temperature which provides the energy for the Ostwald ripening to be activated, the annealing time, and the spatial extension and amplitude of the initial supersaturation of impurities which determines the total number of impurity atoms involved in the phenomenon. The effects of the temperature and time have been studied in detail for many particles as they allow the activation energies and growth laws 
of the phenomenon to be determined. Such studies have been carried out for quite large number of nanoparticles/substrate combinations such as As/GaAs, $\mathrm{Ge} / \mathrm{SiO}_{2}, \mathrm{Si} / \mathrm{Si}, \mathrm{MnAs} /$ $\mathrm{GaAs}, \mathrm{He} / \mathrm{Si}$, and $\mathrm{H} / \mathrm{Si}^{1}{ }^{1-10}$

On the other hand, much less is known on the influence of the initial supersaturation of impurities on the actual sizes and densities of the nanoparticles obtained after a given thermal treatment. Contradictory claims can be found in the literature: for some, increasing the supersaturation (the dose) results in an increase of the sizes of the particles, ${ }^{11,12}$ for others, it results in an increase of their density. ${ }^{13}$ This apparent contradiction largely reflects the experimental difficulty of introducing a controllable amount of impurity atoms into a solid matrix without affecting any other parameters. Moreover, in most cases, the initial supersaturation of impurity atoms introduced in the matrix is depth distributed (ion implantation) and/or surface processes dominate the growth, both situations are rendering the analysis of data difficult.

In this work, we propose a simple structure in which the influence of only the initial supersaturation of impurity atoms on the growth of nanocrystals can be studied. Here, we take advantage of the possibility of monitoring the initial excess of arsenic atoms contained in GaAs layers through their growth temperature, for a fixed overpressure of As. ${ }^{1,2}$

Moreover, the diffusion coefficient of As in GaAs is sufficiently high ${ }^{14}$ to (i) allow the nucleation at a relatively low annealing temperature $\left(600{ }^{\circ} \mathrm{C}\right)$ of As precipitates and (ii) lead to a significant and measurable time evolution of the characteristics of the nanocrystals (size, density) within a reasonable range of time at $750{ }^{\circ} \mathrm{C}$. ${ }^{15}$ The ideal structure should consists of thick GaAs layers containing different amounts of excess As, each layer being uniformly As supersaturated and separated from the others and from the surface by diffusion barriers.

\section{EXPERIMENTAL DETAILS AND METHODOLOGY}

For these reasons, the structure we have grown consists of five 50-nm-thick "low temperature" (LT) GaAs layers grown from the depth to the surface at 150, 175, 200, 225, and $250{ }^{\circ} \mathrm{C}$ respectively, and separated from the others by 7-nm-thick AlAs barriers to minimize As interdiffusion between adjacent "As boxes." Finally, a cap layer of GaAs was grown on top at $600{ }^{\circ} \mathrm{C}$ for $8 \mathrm{~min}$ to protect the surface from As evaporation during further higher temperature annealing. This last step also insured that the nucleation stage of the As precipitates was completed in all the boxes. The samples were then cut into five pieces and further annealed for $30 \mathrm{~min}$ at $600,650,700,750$, and $800^{\circ} \mathrm{C}$, respectively. They were finally prepared for transmission electron microscopy (TEM) investigations on cross-sectional samples using standard preparation techniques involving mechanical grinding and ion milling.

Figure 1 is a typical bright-field (BF) two-beam crosssectional TEM image of the structure annealed at $600{ }^{\circ} \mathrm{C}$. Under such conditions, part of the As precipitates show a high contrast in the form of moiré fringes running perpendicular to the exchange vector between the matrix and the precipitates. ${ }^{2}$ Size distributions can be built up from such

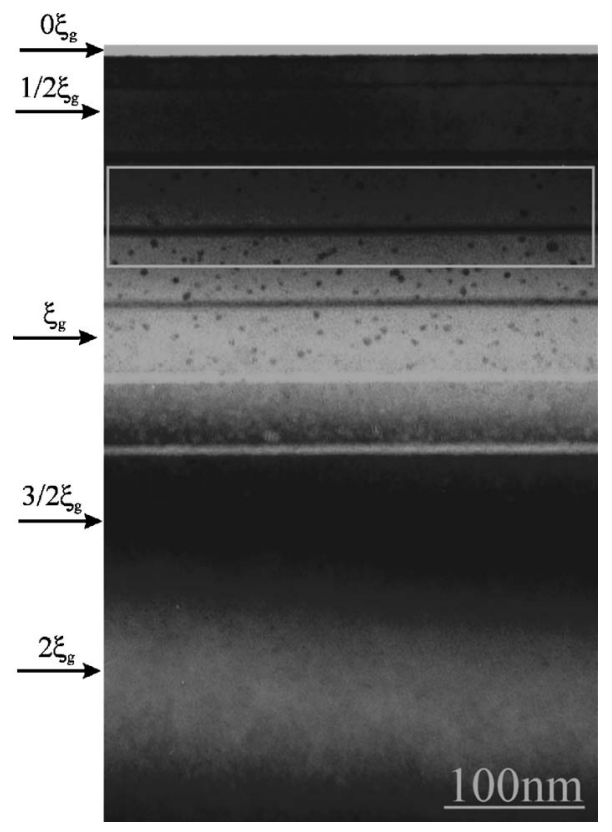

FIG. 1. Typical bright-field cross-sectional (110) images taken under twobeam conditions with $s=0$ and $g=2-20$ of the structure annealed at $600{ }^{\circ} \mathrm{C}$. The corresponding specimen thickness is shown for each black or white thickness fringe. In this image, the area bounded by a white rectangular shape and corresponding to an average thickness of $\frac{3}{4} \xi_{g}$ is chosen for measuring the precipitate density in the layers grown at 200 and $225^{\circ} \mathrm{C}$.

images and the mean radii can be extracted with an accuracy better than $10 \%$. The black/white thickness fringes can be used to measure the thickness of the regions of the sample. ${ }^{16}$ Indeed, maxima (white fringe)/minima (black fringe) are, respectively, seen for thicknesses of $n \xi_{g} /\left(n+\frac{1}{2}\right) \xi_{g}$ where $n$ $=0,1,2, \cdots$ and $\xi_{g}$ is the extinction distance of the electron wave. For a $200 \mathrm{kV}$ accelerating voltage in a GaAs matrix and for $g=220, \xi_{g}$ equals $64 \mathrm{~nm}$. Thus, by using these imaging conditions and by counting the number of thickness fringes, the thickness of the specimen within a definite area of the image can be determined with an accuracy of $\pm \frac{1}{4} \xi_{g}$. In practical cases, areas in the image corresponding to thicknesses of about $\left(n \pm \frac{1}{4}\right) \xi_{g}$ should be preferred since only in these regions did all precipitates show a large amplitude contrast as a result of the small change in crystalline potentials between pure As and GaAs. In Fig. 1, such an area is bounded by a rectangular shape and corresponds to an average specimen thickness of $\frac{3}{4} \xi_{g}$. Knowing the specimen thickness and being able to count all the precipitates, we can deduce their density with an accuracy of about 20\%. By coupling size and density measurements, the volume fraction that the precipitate phase occupies can be calculated with an accuracy of about $50 \%$.

\section{RESULTS}

First of all, the homogeneous distribution of clusters within each "box" is to be noted (see Fig. 1). No cluster appears pinned at or within the AlAs barriers nor outside the LT-GaAs regions.

Figures 2 and 3 summarize the experimental results gathered from all these samples: diameter and density evolutions as a function of growth and annealing temperatures. 


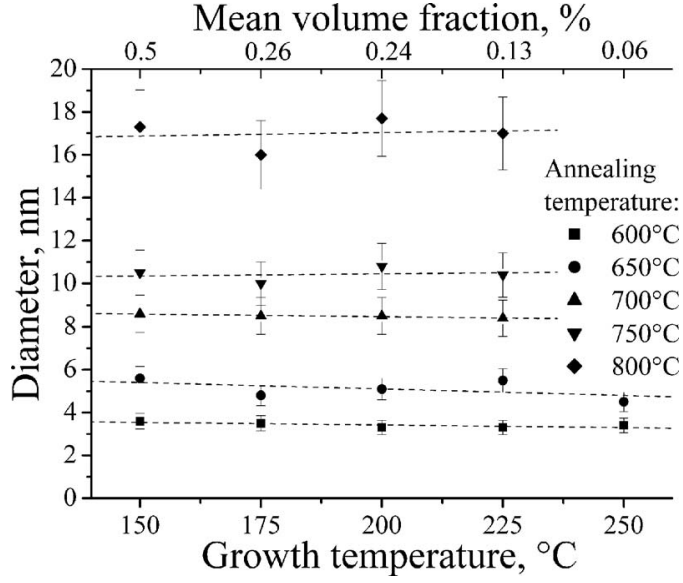

FIG. 2. Mean As cluster diameter evolution as a function of growth temperature shown for different annealing temperatures $(600,650,700,750$, and $\left.800{ }^{\circ} \mathrm{C}\right)$.

The data on the precipitates formed in the layers grown at $250{ }^{\circ} \mathrm{C}$ and annealed at 700,750 , and $800{ }^{\circ} \mathrm{C}$ are omitted due to the lower limits of their density measurements by the TEM method. Since at these growth and annealing conditions only few precipitates have been detected in the 50-nm-thick boxes of a structure in a less than 100-nm-thick TEM prepared specimen, a statistical analysis was not possible.

At first, let us underline the behavior of the characteristics of the precipitate populations as a function of the growth temperature at a fixed annealing temperature. The mean precipitate diameter is independent from the growth temperature (Fig. 2). The precipitate density decreases as the growth temperature increases (Fig. 3)

Alternatively, for a fixed growth temperature, an increase of the annealing temperature results in an increase in the mean size of the precipitates and a decrease of their density. Combining these two measurements, we can extract the volume fraction that the precipitate phase occupies in all samples. We find that this volume fraction is independent of the annealing temperature (not shown) and only depends on the growth temperature. We have checked that the growth of

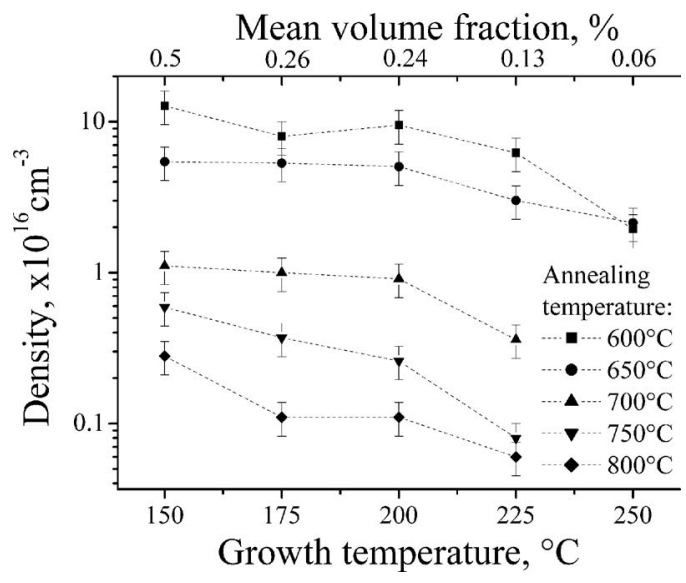

FIG. 3. Mean As cluster density evolution as a function of growth temperature shown for different annealing temperatures $(600,650,700,750$, and $\left.800^{\circ} \mathrm{C}\right)$.

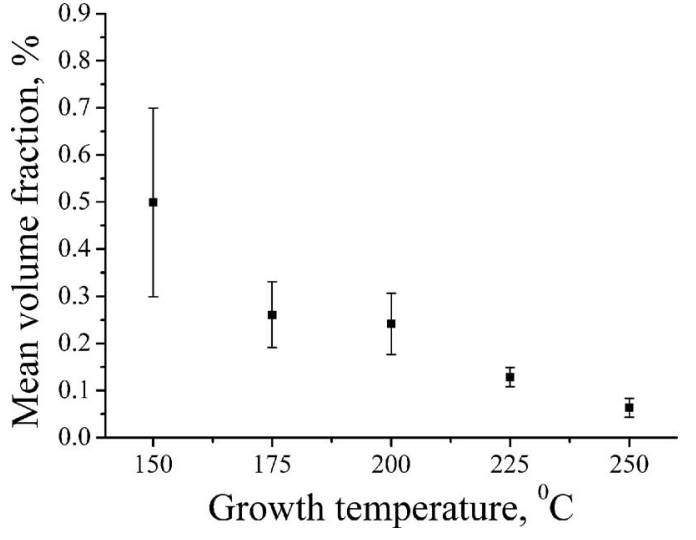

FIG. 4. Mean As cluster volume fraction evolution as a function of growth temperature.

these precipitates is conservative within each box. These observations prove that the precipitate nucleation stage was completed during the growth of the structures and prior to annealing and that the precipitates grow following a conservative Ostwald ripening during annealing. We also confirm here the finding of Ref. 17 that thin AlAs layers do act as diffusion barriers for As in GaAs.

The volume fraction that the precipitated phase occupies can be quantitatively estimated by averaging the results obtained on all the samples grown at the same temperature but annealed at different temperatures. Results are plotted in Fig. 4. For this figure, we see that by varying the growth temperature from 150 to $250{ }^{\circ} \mathrm{C}$ we have spanned almost one decade of initial As supersaturation from about $0.5 \%$ to $0.06 \%$ in excess of the regular stoichiometry of GaAs. Clearly, our results show that the initial supersaturation of As has no influence on the mean size of the precipitates obtained after nucleation and Ostwald ripening at a given temperature (Fig. 2 , upper axe). Alternatively, for given annealing conditions, the density of precipitates is proportional to this initial supersaturation (Fig. 3, upper axe). These data are in agreement with the predictions of the theory of Lifshitz and Slyozov ${ }^{18}$ and Wagner ${ }^{19}$ (LSW), one of the theoretical pillars analytically describing the growth of particles via an Ostwald ripening mechanism. This theory is based on the assumptions that the growth is diffusion limited, that the precipitates are round shaped and that they are at an infinitely large distance from one another (zero volume fraction approximation). Within such a description the precipitates do not "interact" directly with their neighbors and the atoms composing the precipitates are emitted towards, or captured from, the matrix. This theory predicts that, for a given annealing temperature $T_{\text {ann }}$, the mean radius of the precipitate population evolve following the time-dependent law,

$$
\bar{r}^{3}-\bar{r}_{0}^{3}=K \frac{D_{0} \exp \left(-E_{\text {act }} / k T_{\text {ann }}\right)}{T_{\text {ann }}} t,
$$

where $\bar{r}$ is the average radius of the particles after annealing for a time t, $\bar{r}_{0}$ is the average radius of the particles at the beginning of the Ostwald ripening regime, $K$ is the constant growth rate, $D_{0}$ is the effective diffusion coefficient of solute atoms in the matrix, $E_{\text {act }}$ is the activation energy of the pre- 


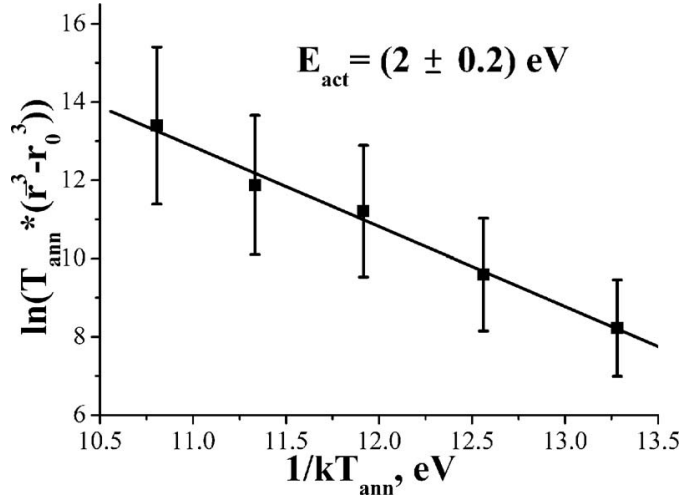

FIG. 5. Arrhenius plot of $\vec{r}^{3}$ dependence on annealing temperature giving the activation energy for As precipitate growth as $2 \pm 0.2 \mathrm{eV}$.

cipitate growth and $k$ is the Boltzman constant. This theory also predicts that the particle-size distributions, scaled by their mean radii, have a time-independent shape. It is also expected that this shape does not depend on the initial supersaturation of solute atoms.

The growth we experimentally observe indeed follows Eq. (1) and its activation energy can be obtained from isochronal anneals. The activation energy for the growth of As precipitates, $E_{\text {act }}$, can be deduced from an Arrhenius plot where $y=\ln \left[T_{\mathrm{ann}}\left(\vec{r}^{3}-r_{0}^{3}\right)\right]=f\left(1 / k T_{\mathrm{ann}}\right)$ and is found to be $2.0 \pm 0.2 \mathrm{eV}$ (Fig. 5) in accordance with a previous report. ${ }^{14}$

Figure 6 shows the experimental precipitate size distributions scaled by their mean radii $\bar{r}$ that we have obtained for the samples grown at different temperatures but all annealed at $600{ }^{\circ} \mathrm{C}$. The shape of this distribution is in good agreement with the one predicted by the LSW theory only for the sample containing the smallest volume fraction of precipitate phase $(\theta=0.06 \%)$ [Fig. 6(a)]. When decreasing the growth temperature from 225 down to $150{ }^{\circ} \mathrm{C}$, i.e., when increasing the As supersaturation, the full width at half maximum a)

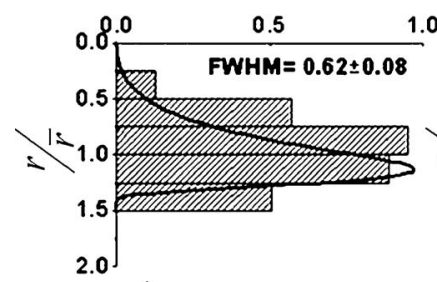

c)

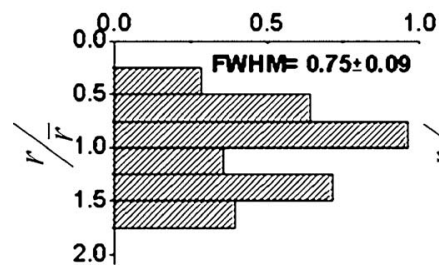

b)

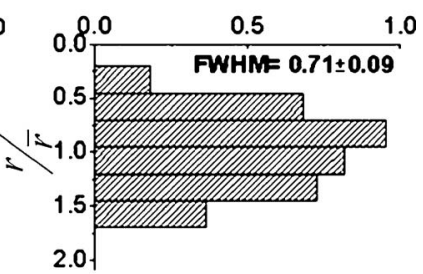

d)

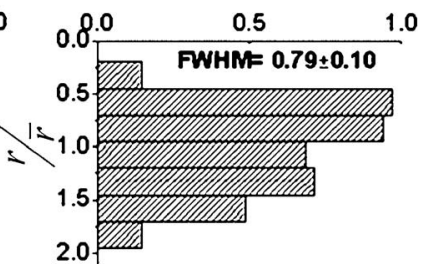

FIG. 6. Size-distribution histograms of As clusters with average radius of $1.7 \mathrm{~nm}$ found in the GaAs layers grown at (a) $225^{\circ} \mathrm{C}(\phi=0.13 \%)$, (b) $200{ }^{\circ} \mathrm{C}(\phi=0.24 \%)$, (c) $175^{\circ} \mathrm{C}(\phi=0.26 \%)$, and (d) $150{ }^{\circ} \mathrm{C}(\phi=0.5 \%)$, after annealing at $600{ }^{\circ} \mathrm{C}$. Full width at half maximum (FWHM) values are given for each histogram. In solid line, the theoretical LSW distribution function is superimposed on the experimental size-distribution histogram for $225^{\circ} \mathrm{C}(\mathrm{a})$.
(FWHM) of the distributions increases from approximately 0.6 to 0.8 , the shape of the size distributions tends to become symmetrical and the characteristic ratio $r_{\max } / \bar{r}$ changes from approximately 1.6 to 2 . These results tend to show that the "zero volume fraction" usually assumed in the LSW theory may not be totally valid in our case. If not valid, the precipitates may directly interact with their neighbors and not only with the supersaturated matrix. Let us discuss this situation.

Under the zero volume fraction approximation, the LSW theory assumes that the diffusion fields surrounding the precipitates do not overlap so that a supersaturation "mean field" exists in the matrix between the precipitates, in dynamical equilibrium with the whole population. The growth or dissolution of a given precipitate of size $r$ is driven by the concentration gradient which exists between this mean field and the concentration of solute atoms in equilibrium with this particular precipitate. Under such an assumption, the growth rate of a precipitate does not depend on the density of the population and thus neither their sizes on the initial supersaturation of solute atoms. This is indeed what we observe. This shows that the approximation is still valid for volume fractions as high as those studied here, which are close to $1 \%$. Alternatively, when the precipitates are too close to each other, the overlapping of the diffusion fields surrounding the precipitates allows the direct transfer of atoms from one precipitate to a neighboring precipitate, a phenomenon which dramatically increases the growth rate of the whole population. ${ }^{23,24}$ This increase of the growth rate has not been observed in our experiments.

Let us estimate the mean distances separating the precipitates in the experiments we have reported in this work. Following Bansal et al. ${ }^{20}$ we express the ratio of the mean distance between neighboring precipitate surfaces, $\bar{\ell}$, to their mean radius, $\overline{\mathrm{r}}$, measured by TEM, as a function of the volume fraction occupied by the precipitates, $\phi$. If the mean diameter of the particles is smaller than the mean distance between them, then

$$
\frac{\bar{\ell}}{\bar{r}}=\frac{\exp (8 \phi)}{3 \phi^{1 / 3}} \Gamma(1 / 3,8 \phi)
$$

which, for the small volume fractions studied here, can be approximated by ${ }^{21}$

$$
\frac{\bar{\ell}}{\bar{r}}=0.554 \rho^{-1 / 3}-2,
$$

where $\rho$ is the volume density.

This ratio is independent of the annealing temperature for a given growth temperature. In other words, as the Ostwald ripening proceeds, the size and the distance between neighboring precipitates increase by the same proportion. An increase of the As initial supersaturation (decrease of growth temperature) results in an increase of the precipitate density, no change in size and thus, to a decrease of the ratio $\bar{\ell} / \overline{\mathrm{r}}$. Figure 7 shows the evolution of this ratio as functions of the growth and annealing temperatures. In our experiments, the mean distance between neighboring precipitates varies from about 5 to $50 \mathrm{~nm}$, i.e., from about 3.5 to 8.5 times their ra- 


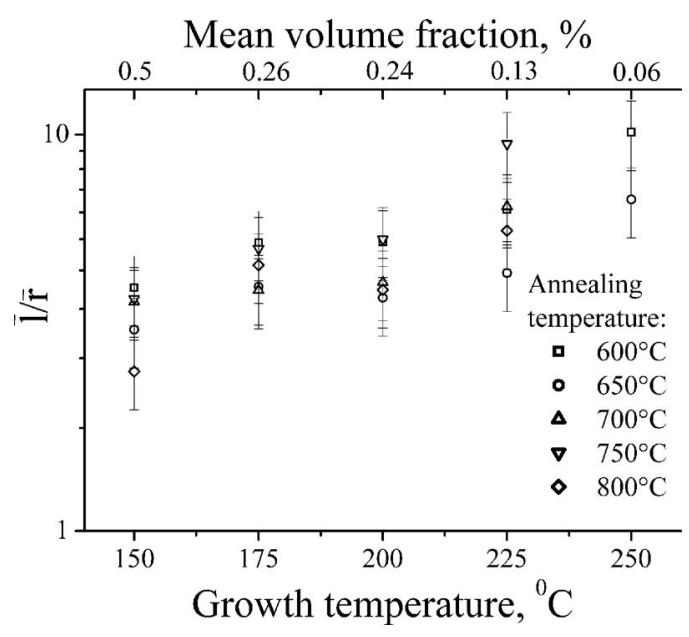

FIG. 7. Evolution of the mean distance between the surfaces of clusters, $\bar{\ell}$, scaled by $\bar{r}$ as a function of growth temperature shown for different annealing temperatures $\left(600,650,700,750\right.$, and $\left.800{ }^{\circ} \mathrm{C}\right)$.

dius. Owing to the small distances involved, the direct interaction between neighboring precipitates appears probable. ${ }^{22-24}$

Following the LSW theory, much of the theoretical work on the ripening phenomenon was aimed at relaxing its central approximation, introducing some interactions between the particles (see Ref. 23 for a review, for example). All of these approaches generally end by showing that direct interactions between particles do not alter the exponent but increase the linear growth constant of the growth rate expressed in the LSW theory. For the small volume fractions studied here, they predict that this constant $K$ vary as $\phi^{1 / x}$, where $x$ takes values equal to 2 or 3 depending on different possible theoretical assumptions. As a result, the average precipitate radius should increase by $30 \%-50 \%$ when increasing the volume fraction of the precipitated phase by a factor of 10. Such an increase, although experimentally measurable, has not been detected in our experiments. Moreover, these theories also predict a broadening and an increased symmetry of the particle radius distributions for increasing supersaturations as compared to results predicted by the LSW theory. While this effect has been probably detected in our experiments, the experimental FWHM of the particlesize distributions increase from 0.6 to 0.8 (Fig. 6), two values significantly larger than those predicted in Ref. 24 for the supersaturations considered here.

From our results, we learn that the diffusion fields surrounding the As precipitates do not extend widely into the matrix, at least not to the point where they overlap. This is probably due to a rather strong capillarity effect between the external surface of the As precipitates and the GaAs matrix. Indeed, direct overlapping of the diffusion fields surrounding neighboring precipitates would immediately result in an increased growth rate of the precipitates for the largest volume fraction and would be detectable by TEM. The mean-field approximation assumed in the LSW theory seems to be mostly valid in our system. However, the decrease of the distance between neighboring precipitates due to an increase of the volume fraction leads to some broadening of the precipitate size distributions, a probable signature of local per- turbations of the diffusion fields surrounding the precipitates and/or of concentration mean field in the matrix.

\section{CONCLUSION}

In summary, we have designed a GaAs based structure in which the influence of the initial supersaturation of solute atoms, here As, on the nucleation and growth of a precipitate phase can be studied. This structure is made of stacked Asrich GaAs layers grown at different temperatures and separated from each other by AlAs diffusion barriers. Pieces of this structure were annealed at various temperatures after a common nucleation annealing at $600{ }^{\circ} \mathrm{C}$ for $8 \mathrm{~min}$. Size distributions and density measurements were carried out by using rigorous TEM methods and the volume fraction that the precipitate phase occupies was deduced from these measurements. We show that the precipitate growth obeys a conservative Ostwald ripening mechanism: whatever the growth temperature, increasing the annealing temperature results in an increase of the precipitate size and a decrease of their density, while the volume fraction that the precipitate phase occupies stays constant. We show that in the $0.06 \%-0.5 \%$ range studied here, the initial supersaturation of As atoms has no effect on the mean size of the precipitates obtained after annealing. Alternatively, the density of precipitates is proportional to the supersaturation. Long As atom diffusion lengths and strong capillarity effects between the external surface of the As precipitates and the GaAs matrix are probably the main reasons for the mean-field approximation assumed in the LSW theory for a zero volume fraction to still hold in our case. However, the increase of the initial As supersaturation results in a continuous broadening of the precipitate size distributions, probably a signature of some local perturbation of the diffusion fields surrounding the precipitates and extending into the matrix when the mean distance between neighboring precipitates becomes very small.

\section{ACKNOWLEDGMENTS}

This work was financially supported by the European Commission through the INTAS Project No. 97-30930, as well as by the Russian Academy of Sciences within the research program on quantum nanostructures.

${ }^{1}$ Z. Liliental-Weber, W. Swider, K. M. Yu, J. B. Kortright, F. W. Smith, and A. R. Calawa, Appl. Phys. Lett. 58, 2153 (1991).

${ }^{2}$ A. Claverie and Z. Liliental-Weber, Mater. Sci. Eng., B 22, 45 (1993).

${ }^{3}$ C. Bonafos, B. Garrido, M. Lopez, A. Perez-Rodriguez, J. R. Morante, Y. Kihn, G. Ben Assayag, and A. Claverie, Appl. Phys. Lett. 76, 3962 (2000).

${ }^{4}$ A. Serres, M. Respaud, G. Ben Assayag, J.-C. Pesant, C. Armand, and A. Claverie, J. Magn. Magn. Mater. 295, 183 (2005).

${ }^{5}$ A. Claverie, B. Colombeau, B. de Mauduit, C. Bonafos, X. Hebras, G. Ben Assayag, and F. Cristiano, Appl. Phys. A: Mater. Sci. Process. 76, 1025 (2003)

${ }^{6}$ F. Cristiano, N. Cherkashin, X. Hebras, W. Lerch, S. Paul, and A. Claverie, Appl. Phys. Lett. 83, 5407 (2003).

${ }^{7}$ C. Bonafos, B. Garrido, M. Lopez, A. Perez-Rodriguez, J. R. Morante, Y. Kihn, G. Ben Assayag, and A. Claverie, Mater. Sci. Eng., B 69, 380 (2000).

${ }^{8}$ C. Bonafos, D. Mathiot, and A. Claverie, J. Appl. Phys. 83, 3008 (1998). ${ }^{9}$ J. Grisolia, A. Claverie, G. Ben Assayag, S. Godey, E. Ntsoenzok, F. Labhom, and A. Van Veen, J. Appl. Phys. 91, 9027 (2002).

${ }^{10}$ V. Raineri, M. Saggio, and E. Rimini, J. Mater. Res. 15, 1449 (2000).

${ }^{11}$ N. A. Bert et al., Phys. Solid State 35, 1289 (1993). 
${ }^{12}$ F. Iacona, G. Franzo, and C. Spinella, J. Appl. Phys. 87, 1295 (2000).

${ }^{13}$ B. Colombeau, F. Cristiano, J-C.. Marrot, G. Ben Assayag, and A. Claverie, Mater. Res. Soc. Symp. Proc. 669, J4.8.1 (2001).

${ }^{14}$ N. A. Bert, V. V. V. Chaldyshev, Yu. G. Musikhin, A. A. Suvorova, V. V Preobrazhenskii, M. A. Putyato, B. R. Semyagin, and P. Werner, Appl. Phys. Lett. 74, 1442 (1999).

${ }^{15}$ M. Toufela et al., Proceedings of SIMC-XI Conference, 2000, pp. 85-88.

${ }^{16}$ D. B. Williams and C. B. Carter, Transmission Electron Microscopy, Imaging III (Plenum, New York, 1996), p. 369.

${ }^{17}$ M. N. Chang, K. C. Hsieh, T.-E. Nee, and J.-I. Chyi, J. Appl. Phys. 86,
2442 (1999)

${ }^{18}$ I. M. Lifshitz and V. V. Slyozov, Sov. Phys. JETP 35, 479 (1958).

${ }^{19} \mathrm{C}$. Wagner, Z. Elektrochem. 65, 581 (1961).

${ }^{20}$ P. P. Bansal and A. J. Ardell, Metallography 5, 97 (1972).

${ }^{21}$ S. Chandrasekhar, Rev. Mod. Phys. 15, 1 (1943).

${ }^{22}$ J. S. Tsang, C. P. Lee, S. H. Lee, K. L. Tsai, C. M. Tsai, and J. C. Fan, J. Appl. Phys. 79, 664 (1996).

${ }^{23}$ P. W. Voorhees, Annu. Rev. Mater. Sci. 22, 197 (1992).

${ }^{24}$ K. Tsumuraya and Y. Miyata, Acta Metall. 31, 437 (1983). 